\title{
Preparing the Would-be Economists in Condition of the Electronic Information Education Environment
}

\author{
Nelly Savelyeva \\ Dept of Foreign Languages and Educational Technologies \\ Ural Federal University named after the first President of \\ Russia, B.N. Eltsyn \\ Ekaterinburg, Russia \\ nellik1983@mail.ru \\ Elena Gnatyshina \\ Dept of Training Teachers of Vocational Training and \\ Subject-Specific Methods \\ South-Ural State Humanitarian-Pedagogical University \\ Chelyabinsk, Russia \\ mopr9@mail.ru
}

\author{
Natalya Uvarina \\ Dept of Training Teachers of Vocational Training and \\ Subject-Specific Methods \\ South-Ural State Humanitarian-Pedagogical University \\ Chelyabinsk, Russia \\ nuvarina@yandex.ru \\ Natalya Pakhtusova \\ Dept of Training Teachers of Vocational Training and \\ Subject-Specific Methods \\ South-Ural State Humanitarian-Pedagogical University \\ Chelyabinsk, Russia \\ pakhtusovana@cspu.ru
}

\author{
Yulya Berngardt \\ Dept of Foreign Area Studies (student) \\ Ural Federal University named after the first President of Russia, B.N. Eltsyn \\ Ekaterinburg, Russia \\ berngardt2504@gmail.com
}

\begin{abstract}
The changes taking place in the modern world economic and socio-cultural space contribute to the growth of intercultural interaction, the expansion of cooperation in international educational projects, and professional contacts between representatives of different cultures. All this requires university graduates to be professionally competent, whose inherent indicators are fluency in a foreign language and norms of intercultural communication. The intercultural orientation of modern social thought is implemented in educational policy, considering a modern university graduate as a person, not just possessing specific competences and knowledge, but also capable of cooperating and constructive multicultural dialogue, interacting with people of different cultures and knowing the system of socially significant world values. In modern pedagogical science, considerable experience has been accumulated in preparing students of different specialities for intercultural interaction, forming and developing the tolerance, intercultural communicative competences, educating the younger generations in a multicultural world. Nevertheless, the issue of preparing would-be economists for intercultural interaction in the context of the electronic information educational environment remains poorly developed today.
\end{abstract}

Keywords - intercultural interaction; would-be economists; information approach; ternarity; electronic informational educational environment; foreign language; blended learning.

\section{INTRODUCTION}

Internationalization has been considered to be one of the major trends in the development of higher education in recent years. However, many would agree that, particularly at institutional level, there is often a gap between the rhetoric and the reality of internationalization. How to promote internationalization strategies and how to cope with various pressing trends and challenges at institutional level are questions which are still begging for appropriate replies, and from these replies, appropriate solutions [1].

The intercultural orientation of modern social thought is implemented in educational policy, which considers the modern graduate of a higher education institution as a person, not only possessing specific competencies and knowledge, but also capable of cooperation and constructive multicultural dialogue, interaction with representatives of different cultures, orientated in a system of socially significant world values. There is no doubt that the modern higher school, whose main 
reference points are democratization and humanization, makes a significant emphasis in favor of preparing students for intercultural interaction. In the indicated context, the preparation of an individual for intercultural interaction, which determines its ability for constructive cooperation with representatives of different cultures, seems especially relevant for a citizen of a multinational state.

The huge potential for this lies in the electronic information educational environment of the university, which, in the context of the implementation of modern documents in the field of higher education, is seen as a modern, focused component of the educational process, which forms the motivation and need for study, which allows rethinking and developing the students' communication skills.

The genesis of the studied problem allowed us to draw a conclusion about the increased scientific interest in the postulates of multicultural pedagogy.

The works devoted to the consideration of foreign experience in the formation and development of multicultural education by O. V. Khukhlaeva\&O. E. Khukhlaeva [2], A. N. Dzhurinsky [3], L. L. Suprunova and Y. S. Sviridenko [4], E. R. Khakimov [5]. The analysis of bases of realization of multicultural education is carried out in G. Zh. Dautova's researches [6], V. A. Ershov [7], L. V. Kolobova [8], V. V. Makaeva and Z. A. Malkova [9], R. Z. Khairullin [10]. It is noteworthy that many researchers highlight and emphasize tolerance as the main characteristic of a person capable of comfortable life in an intercultural environment. So, for example, dissertation research of T. I. Likhacheva [11], I. V. Mirotvorskaya [12], E. L. Pastukhova [13], R. I. Khuzin [14], O. V. Korotkikh [15] and others are devoted to the study of manifestations of tolerance in children and adolescents.

Among the higher educational institutions conducting research in the field of intercultural communication, the leading position is undoubtedly occupied by MSU named after M. V. Lomonosov, whose teachers and scientists are engaged in the development of both theoretical and practical aspects of intercultural issues. In addition, MSU. M. V. Lomonosova actively supports scientists of other universities in the development of educational programs of the specialty "Linguistics and intercultural communication". On the basis of this university is published and the first textbook on intercultural communication [16].

During this period, Europe and Russia are actively developing linguodidactics, containing in its content intercultural aspects of teaching individual languages. N. D. Galskova and N. I. Gez - authors of the first manual on linguodidactics, devote their research to the influence of various aspects of culture on the process of teaching foreign languages. Adhering to the opinion of $G$. Neiner and $G$. Gunfeld, N. D. Galskova and N. I. Gez talk about the emergence of a new direction in the domestic communicative methodology, in which we are talking about "socio-cultural approach", "integrated country studies", "cultural approach", "intercultural learning" [17].

A significant contribution to the formation of intercultural communication as a discipline in Russia makes $\mathrm{V}$. V.
Safonova, who focuses in her research on the interaction between the level of proficiency in native and non-native languages and the movement of the individual in his multicultural development from one degree to another. It should be noted that in her research V. V. Safonova relies on current world concepts in the field of linguistic training, highlighting the presence of a number of negative trends that can prevent the successful implementation of the foundations of cultural and intercultural development of the individual in the practice of linguistic education [18].

Special attention in the domestic pedagogical science is paid to the position of V. L. Pluzhnik, which most accurately, in our opinion, formulates the content of the concept of "intercultural communicative competence", which means the ability to interact on the basis of socio-cultural and linguistic norms and universal cultural values; to overcome conflicts in the process of contact of professional cultures and styles; use variable and empathy-based skills [19].

Separately, we would like to note the dissertation study by E. B. Bystray, devoted to the study of a special type of human activity for the implementation of the acquired knowledge, skills and values of interpersonal interaction with representatives of different cultures and Nations. The scientist characterizes this process as intercultural competence [20].

\section{RESEARCH QUESTIONS}

1) to present the historiography of the problem of preparing future economists for intercultural interaction in the conditions of electronic information educational environment of the university and to analyze its current state;

2) to develop a system of training future economists for intercultural interaction in the electronic information educational environment of the university;

3) to determine the pedagogical conditions of its effective functioning;

4) to develop and test in the educational process in higher education educational and methodological support aimed at preparing future economists for intercultural interaction.

\section{RESEARCH METHODS}

The study will be conducted using a set of theoretical and empirical methods.

Theoretical methods: a) analysis of normative documents on education used to justify the relevance of the problem and identify the legal possibilities for its solution; b) historicalpedagogical analysis is used to build a historiography of the research problem; C) theoretical and methodological analysis allows us to formulate the original position of the research; $d$ ) conceptual and terminological analysis is aimed at the description of the conceptual field problems; d) system analysis provides the basis for holistic treatment of the problem.

Empirical methods: a) research and generalization of effective experience and mass practice of training future economists; b) ascertaining experiment to assess the level of 
Thus, the logic of our study suggests:

1) assessment of structural changes in the developed pedagogical system of training future economists for intercultural interaction by calculating the length of the minimum program that allows you to translate one set of States into another (competent measurement of information);

2) assessment of changes in the amount of diversity of the source (teacher) and receiver (students) of educational information of intercultural orientation in a foreign language as a result of its transmission (competent processing of information);

3) assessment of replenishment of vocabulary in a foreign language of the receiver of information by quantity of the received semantic (semantic) and pragmatic (axiological) information (competent assessment and definition of one-time volume of educational information according to the level of language development and possibility of interchange between all participants of educational process).

Processing of educational information of intercultural orientation in a foreign language in the logic of our study involves its change by selection in terms of expediency, usefulness and efficiency through filtering, compression and editing. In order to assess the quantitative and qualitative indicators of the presented educational information from the standpoint of the information approach, it is also advisable to involve a mathematical apparatus that ensures the efficiency, manageability and predictability of the pedagogical process.

In this regard, it should be noted the presence in the studies of modern scientists of various disciplinary directions of reasoning about the ternarity of thought processes. Binary manifests itself in the modality and various formats of information signals, in the three-level representation of the semantics of communication messages, in the three-fold repetition of the studied material. Ternary format of information presentation is the most comfortable for perception and contributes to the efficiency of thought processes.

In modern pedagogical science, considerable experience has been accumulated in the preparation for intercultural interaction among students of different profiles, the formation and development of tolerance to representatives of other cultures, intercultural communicative competencies, and education of younger generations in a multicultural world. However, the question of preparing future economists for intercultural interaction with ternary representation of educational signals in the conditions of electronic information educational environment of the university today remains poorly developed.

The urgency of the problem of preparing future economists for intercultural interaction in the conditions of electronic information educational environment of the university with the use of technology of ternary presentation of educational information is caused by the need for:

- formation of the personality of the future economist, able to navigate in socially significant values, to carry out effective interaction with different people in the situation of 
intercultural dialogue, which is conditioned by the social order and the regulatory support of the modern educational policy of the Russian Federation;

- development of theoretical bases of preparation of future economists to the investigated phenomenon in the conditions of electronic information educational environment of higher education institution with application of technology of ternary representation of educational information;

construction and approbation of the system and pedagogical conditions providing productive process of preparation of future economists for intercultural interaction in the conditions of electronic information educational environment of higher education institution.

In this regard, the idea of this study is to organize the process of preparation for intercultural interaction as a reflection in the consciousness and behavior of the future economist of knowledge about the cultural, national, political and economic characteristics of the country of the studied language, contributing to the creation of an image of a popular economist of a new generation, with the aim of competent professional activity; able to see the prospects and plan strategies and tactics for the development of the enterprise, fluent in a foreign language and skills of effective intercultural dialogue-which in turn will significantly improve the quality of service and profitability of domestic enterprises and satisfy the increased requirements of the state and society to graduates of economic faculties.

The idea of the present study is consistent with the "Russian Model of education for innovative economy for the period till 2020", providing for innovative development and competitiveness of Russia, and not contrary to the basic principles of the national priority project "Education 20192024" which supports innovative practices in educational institutions and are aimed at ensuring global competitiveness of Russian education and upbringing of harmoniously developed and socially responsible personality.

\section{CONCLUSION}

The scientific novelty of this study is:

1) determination of methodological strategy of research of a problem of preparation of future economists for intercultural interaction-interrelation of system, activity, cultural and information approaches which combination provides integrity and functionality of the organization of this process;

2) in the development on the basis of the abovementioned methodological approaches of the information pedagogical system of preparation of future economists for intercultural interaction, consisting of motivational-target, content-procedural, correctional-evaluation components, implemented taking into account the General pedagogical and specific principles (communicative partnership and cooperation, inclusive culture, facilitation);

3) identification of a complex of pedagogical conditions of effective functioning of the developed system, including: use of properties of electronic information educational environment of higher education institution and features of circulation of educational information through an assessment of degree of information saturation of the carried out pedagogical process and the characteristic of mechanisms of reception, transfer, recognition, transformation and storage of educational information in a foreign language; the use of methods of mixed type of teaching (Blended Learning) a foreign language using the technology of ternary presentation of educational information (visual modality, auditory modality, kinesthetic modality);

4) development of criteria-diagnostic apparatus for assessing the readiness of future economists to intercultural interaction.

The theoretical significance of the study is:

1) presentation of the historiography of the problem, substantiation of the role of effective intercultural interaction for the professional activity of economists, which makes a certain contribution to the solution of the problem, enriching the theory of pedagogy with historiographical information on the problem of research;

2) clarification of the concept of "intercultural interaction", "preparation of future economists for intercultural interaction", "electronic information educational environment of the university", "ternarity", "mixed learning", which expands the conceptual and terminological apparatus of higher school pedagogy;

3) realization of interrelation of system, activity, cultural, information and axiological approaches to the solution of the problem of preparation of future economists for intercultural interaction in the conditions of EIEE(Electronic information and educational environment) of higher education institution that supplements methodological bases of the theory of formation of professional competence of experts of different profiles, focusing in the plane of formation of the above-mentioned competence;

4) determining the features of the circulation of educational information in a foreign language and the description of the developed pedagogical system in the language of information theory, assessing the degree of information saturation of the educational process.

We justify the necessity and sufficiency of the stated approaches:

- Firstly, the aim of the study is to develop a pedagogical system for training future economists for intercultural interaction in the electronic information environment of the university. To understand and determine its structure, substantiate the component composition and identify intrasystem relationships, it is necessary to turn to the system approach.

- Secondly, effective preparation for intercultural interaction involves achieving results only in the relevant activities, in a specialized educational process; therefore, it is necessary to use the activity approach.

- Thirdly, the study of the essence of the process of intercultural interaction, its norms and principles in the 
[6] G. Zh. Dautova, Development of multicultural education in the Volga region, Kazan, 2004, 435 p. the culturalogical approach that promotes the formation of personality as a representative of a culture with an adequate attitude to the cultural heritage of different cultures and nations.

- Fourthly, the implementation of the developed system is carried out in the conditions of electronic information educational environment of the university. The information approach allows one to define features of circulation of information in the developed pedagogical system, to describe the presented pedagogical in the language of the theory of information, to reveal mechanisms of reception, transfer, recognition, transformation and storage of educational information.

Thus, the system approach allows one to consider a holistically pedagogical system from a position of its structure, component structure and interrelations. The activity approach proves the most optimum conditions of development of the personality of the future economist in the course of the international activity. The culturological approach provides a meaningful characteristic of the process of preparing future economists for intercultural interaction. Information reveals the degree of information saturation of the educational process carried out to prepare future economists for intercultural interaction.

\section{References}

[1] A. Barrows, L. Conley, Internationalization of higher education: an institutional perspective, UNESCO, 2000, p. 5.

[2] O. V.Khukhlaeva, E. R. Khakimov, O. E. Khukhlaev, Multicultural education: a textbook for bachelors, Yurayt Publishing House, 2017, 283 $\mathrm{p}$.

[3] A. N. Dzhurinsky, Multicultural education in multinational society, $2^{\text {nd }}$ ed., Moscow: YURAYT, 2016, 257 p.

[4] L. L.Suprunova , Y. S. Sviridenko, Multicultural education, Publishing house "ACADEMIA", 2013, 240 p.

[5] E. R. Khakimov, Designing the practice of multicultural education on the basis of the polyparadigm approach, Izhevsk, 2012, $296 \mathrm{p}$.
[7] V. A. Ershov, Multicultural education in the system of General education of secondary school students, Moscow, 2000, $185 \mathrm{p}$.

[8] L. V. Kolobova, Formation of the personality of the schoolchildren in multicultural education, Orenburg, 2006, 349 p.

[9] V. V. Makaev, Z. A. Malkova, L. L. Suprunova, Multicultural education-actual problem of modern school, Pedagogy, no. 4, pp. 3-9, 1999.

[10] R. Z. Khairullin, State and prospects of development of national education systems in Russia. Retrieved from: http:tatarhistory.narod.ru/federal.htm

[11] T. I. Likhacheva, Formation of tolerance of teenagers in system of educational work of educational institutions, Stavropol, 2008, 228 p.

[12] I. V. Mirotvorskaya, Formation of tolerance among students of senior classes of secondary schools in the process of legal education, Cheboksary, 2004, 204 p.

[13] E. L. Pastukhova, The formation of tolerance among students of educational institutions in the process of learning history, Moscow, 2004, 230 p.

[14] R. I. Khuzin, Formation of tolerance in primary school students by means of ethnopedagogics, Kazan, 2009, 205 p.

[15] O. V. Korotkikh, Education of children in the spirit of peacefulness in the traditions of folk pedagogy: monograph, Moscow: research center INFRA-M, 2016, 127 p.

[16] S. G. Ter-Minasova, Language and intercultural communication, Moscow, 2000, $624 \mathrm{p}$

[17] N. D. Galskova, N. I. Gez, Theory of teaching foreign languages. Linguodidactics and methodology, Moscow: Publishing center "Academy", 2008, 545 p.

[18] V. V. Safonova, Co-study of languages and cultures in the mirror of world trends in the development of modern language education. Retrieved from: https://cyberleninka.ru/article/n/soizuchenie-yazykov-ikultur-v-zerkale-mirovyh-tendentsiy-razvitiya-sovremennogoyazykovogo-obrazovaniya.

[19] V. L. Pluzhnik, The main components of modelling the process of formation of foreign language intercultural communicative competence in higher education. Retrieved from: https://cyberleninka.ru/article/n/osnovnye-komponenty-modelirovaniyaprotsessa-formirovaniya-inoyazychnoy-mezhkulturnoykommunikativnoy-kompetentsii-v-vuzovskom.

[20] E. B. Bystray, The formation of the experience of intercultural competence of the would-be teachers in pedagogical interaction. Retrieved from: http://www.dissercat.com/content/formirovanie-opytamezhkulturnoi-kompetentnosti-budushchego-uchitelya-vpedagogicheskom-vzai\#ixzz5fcFejARR 